\title{
Managing an optics career in turbulent times
}

\section{Wayne Knox}

Wayne H. Knox, "Managing an optics career in turbulent times," Proc. SPIE 9663, Eighth International Topical Meeting on Education and Training in Optics and Photonics, 966303 (6 October 2003); doi: 10.1117/12.2208371

SPIE Event: Eighth International Topical Meeting on Education and Training in Optics and Photonics, 2003, Tucson, Arizona, United States 


\title{
Managing an Optics Career in Turbulent Times
}

\author{
Wayne H. Knox, Director and Professor of Optics, The Institute of Optics \\ Rochester, NY 14627
}

The Institute of Optics was established in 1929, and has granted over 2360 degrees in Optics at BS, MS and PhD levels. The Institute currently has over 1900 living alumni in the field working in many different professions, as well as 100 undergraduate and 100 graduate students currently in the program. Here in Rochester, as in many other Optics education organizations, the recent turbulent (exciting!) times in the Optics profession caused in many ways by the "Telecommunications Bubble" of 2000-2001, significant changes have been taking place. As always, Optics is an exciting field full of opportunity, and managing an Optics career during these times of rapid change is in itself a challenge. In the past, people were assuming that they would change jobs perhaps once or twice during their professional lifetime, however today it is safer to assume that you will change jobs up to 6 or 7 times during your professional career. This is a significant shift, carrying many implications for Optics professionals, and is particularly tough for twocareer families. Optics education is critical to members of the profession - not only when entering, but on a continuous basis through continuing education programs, summer courses, short-courses at conferences, etc. Eric Hoffer has said "In a time of drastic change it is the learners who inherit the future. The learned usually find themselves equipped to live in a world that no longer exists."

In the post-bubble economy, we now find sanity re-appearing in many sectors. Some great old-fashioned traditions are actually coming back again. At Bell Labs, we had many post-doctoral scientists, and for many, the post-doc was a very important step in their career. I did a post-doc, too. Some people even did two or three post-docs before they found a 'permanent' position. Yet, in the wild days of 2000, it seemed that the very idea of a post-doc was disappearing, as it was the invention of a time where there were no 'permanent' positions. The post-doc position is returning to its rightful place in Optics as an important career development stage.

How can you best prepare yourself for a career in Optics in an uncertain and exciting world ? First, I would say - you must find your passion - the thing that truly gets you excited. You should make sure that you get a solid, broad education in fundamentals, with lots of lab experience, and prepare yourself to be flexible. Then, as your career progresses, wherever you are, you should continuously ask yourself - "what do I really want to be doing in 5 or 10 years?" And then, ask yourself "are the things that I am doing now consistent with what I want to be doing in 5 or 10 years?" 